\title{
EVALUACIÓN SENSORIAL DE DIFERENTES PRESENTACIONES COMERCIALES DE DORADA (SPARUS AURATA L.) DE ACUICULTURA
}

Sensory analysis of different aquaculture gilthead sea bream (Sparus aurata L.) commercial presentations.

\section{Santaella* M., Martínez Graciá C., Periago M.J., Santaella J.}

Departamento de Tecnología de Alimentos, Nutrición y Bromatología. Facultad de Veterinaria. Universidad de Murcia. Campus de Espinardo, 30100, Murcia, España.

* Autor para la correspondencia: Marina Santaella, Tel:+34 868888263 Fax: +34 868888497. E-mail: marinasp@um.es

Historial del artículo:

Recibido: 8 noviembre 2012

Aceptado: 23 diciembre 2012

\section{RESUMEN}

El análisis o evaluación sensorial, se puede definir como el análisis de los alimentos a través de los sentidos. Desde la antigüedad se ha utilizado la valoración sensorial para aceptar o rechazar los alimentos, así como para asignarle un determinado valor comercial. El análisis sensorial presenta dos grandes ventajas: la rapidez y la sencillez, sin embargo, las sensaciones que motivan al rechazo o aceptación varían con el tiempo y el momento que se perciben, dependiendo tanto de la persona como del entorno, con lo que es necesario objetivar y normalizar los términos y las condiciones que puedan influir en las determinaciones. En el presente estudio se llevó a cabo el análisis sensorial de cuatro presentaciones diferentes de dorada almacenadas en hielo: enteras, fileteadas, fileteadas y envasadas al vacío, y marinadas con zumo de limón y envasadas al vacío. El estudio se realizó para determinar el momento en el cual los distintos tipos de muestras eran rechazadas organolépticamente. Para ello un panel de catadores semientrenados evaluaron los atributos de apariencia, olor, flavor y textura, en los filetes de dorada cocinados, utilizando una escala puntuada. En las cuatro presentaciones comerciales, las puntuaciones otorgadas por el panel para la frescura decrecen linealmente a medida que pasan los días de permanencia en hielo. Los miembros del panel de catadores consideraron organolépticamente inaceptables las doradas enteras, las fileteadas y las fileteadas al vacío, en el día 22 de almacenamiento en hielo, sin embargo, las doradas marinadas no alcanzaron esta consideración en los 22 días que duró el estudio.

Palabras clave: Análisis sensorial, doradas. 


\begin{abstract}
The analysis or sensory test may be defined as an analysis of food by means of the senses. Such sensory evaluations have been used from ancient times to accept or reject food, as well as to designate its commercial value. Sensory analysis provides two important advantages: it is quick and it is simple. However, the senses which give rise to acceptance or rejection do vary over time and at the moment of perception. This depends as much on the person as on the environment. A reliable measure requires objectivity and normative regulation of terms and conditions that can influence specific evaluations. The current study has carried out sensory analysis of four different githhead sea bream presentations (whole, fillets, vacuum packed fillets, and marinated in lemon juice and vacuum packed fillets). The study was done as a quality test in order to determine the moment in which the fish is organoleptically rejected. In the four presentations, the scores given for freshness, decreased linearly according to time spent in ice. The taste panel members found the whole, the filleted and the vacuum filleted sea bream organoleptically unacceptable by the 22 nd day on ice. Nevertheless, marinated sea bream were not so considered by the 22nd day.
\end{abstract}

Key words: Sensory analysis, gilthead sea bream.

\section{INTRODUCCIÓN}

Los cambios bioquímicos, físicos y microbiológicos que ocurren tras la muerte del pescado originan pérdida de frescura y un deterioro en la calidad global. Estas modificaciones son dependientes del tipo de especie, del manejo del pescado y de las condiciones de almacenamiento y conservación (Dalgaard, 2003).

Así los signos externos del deterioro en el pescado se perciben a través de los órganos de los sentidos, y por ello se denominan cambios sensoriales, y pueden ser apreciados fácilmente por los consumidores (Dalgaard, 2003). Los métodos organolépticos o sensoriales evalúan características del pescado como el aspecto, la textura, el olor y el color, valorando los cambios desarrollados progresivamente en el pescado hasta su deterioro. Son los más utilizados en las inspecciones diarias de lonjas, puertos y mercados, y en ellos se apoyan los inspectores de los alimentos para determinar la frescura, la calidad e idoneidad de los diferentes lotes de pescado y los consumidores para decidir la adquisición y compra.

La mayoría del pescado fresco almacenado en hielo, sigue un mismo patrón de deterioro, resultante de los cambios bioquímicos, químicos y microbiológicos que se producen tras la captura, que pueden clasificarse en cuatro fases tal y como se muestra en la Tabla 1 (Huss, 1999).

Inmediatamente después de la muerte el músculo del pescado está totalmente relajado y la textura flexible y elástica generalmente persiste durante algunas horas dependiendo del tamaño de pescado. Posteriormente, durante la aparición del rigor mortis, el músculo se contrae produciéndose el cambio más drástico. Esta condición se mantiene durante uno o más días dependiendo del tamaño del pescado, tiempo tras el cual se resuelve el rigor relajándose nuevamente y recuperando la flexibilidad, pero no la elasticidad previa al rigor (Huss, 1999).

El aroma y flavor son las características que con mayor frecuencia se asocian con la calidad del pescado. El mal olor del pescado se debe principalmente a la reducción bacteriana de óxido de trimetilamina a trimetilamina, la cual es responsable del olor típico a carne deteriorada del pescado (Love, 1980; Connel, 1990). Los peces de agua dulce, sin embargo, contienen cantidades muy bajas de oxido de trimetilamina, y en este caso los olores desagradables provienen de carbonilos y alcoholes procedentes de los ácidos grasos poliinsaturados (Cadwallader, 2000). Otros parámetros indicadores del deterioro y responsables del flavor son la 
Tabla 1. Cambios en pescado fresco durante su almacenamiento en hielo (Huss, 1999)

\begin{tabular}{|c|c|}
\hline Fase 1: & $\begin{array}{l}\text { - El pescado está muy fresco } \\
\text { - Sabor y olor característico de la especie, que casi siempre se describe como aroma } \\
\text { a algas marinas, dulce y delicado. }\end{array}$ \\
\hline Fase 2: & $\begin{array}{l}\text { - Existe una pérdida del olor y sabor característico. } \\
\text { - La carne permanece neutra sin aparecer aromas extraños. } \\
\text { - } \quad \text { La textura se mantiene agradable. }\end{array}$ \\
\hline Fase 3: & $\begin{array}{l}\text { - Aparecen los primeros signos de deterioro con la presencia de aromas extraños } \\
\text { debido a la formación de compuestos volátiles. } \\
\text { - Al principio pueden aparecer olores y sabores ligeramente ácidos, afrutados y } \\
\text { ligeramente amargos, especialmente en peces grasos. } \\
\text { - La textura se torna suave y aguada o dura y seca. } \\
\text { - Durante las últimas etapas encontramos aromas a col, amoniacales, sulfurosos o } \\
\text { rancios. }\end{array}$ \\
\hline Fase 4: & - El pescado puede considerarse deteriorado o podrido. \\
\hline
\end{tabular}

concentración de las bases volátiles y de los productos de degradación de nucleótidos y aminoácidos. El metabolismo del ATP se ve alterado en peces sometidos a gran estrés durante la captura y el sacrificio, generándose metabolitos responsables de sabores salados-ácidos y amargos (Rasmussen, 2001). Además, el contenido en ácidos grasos poliinsaturados también afecta negativamente al flavor, ya que, si el pescado no se conserva y almacena adecuadamente, estos tienen tendencia a oxidarse muy rápidamente y enranciar el producto (Ludovico-Pelayo y col., 1984).

La firmeza es otra de las características importante para evaluar la calidad de la carne del pescado y fundamental en el momento de su comercialización. Depende de diversos factores como la especie, la edad, el tiempo de almacenamiento, el estado nutricional, el sacrificio etc. Comparada con la carne de animales terrestres, que contienen más de un $23 \%$ de colágeno, el contenido en los peces no supera el 3\% (Periago y col., 2005). Este bajo porcentaje en colágeno es el responsable de que la carne de pescado resulte menos dura y menos estable al cocinado que la carne de ternera (Hatae y col., 1990). La textura se encuentra también relacionada con los cambios de $\mathrm{pH}$ post-mortem de la carne, ya que en general, la dureza se reduce cuando el pH aumenta (Love, 1980). Otro factor que afecta a la textura de la carne del pescado, es el estrés sufrido por el pez antes del sacrificio. Así en pescados muy estresados los niveles de glucógeno son bajos, por lo tanto no se produce suficiente ácido láctico por respiración anaeróbica y el pH se mantiene cerca de la neutralidad. A pesar de estas particularidades, al tener la musculatura de pescado un menor contenido de glucógeno que la musculatura de los mamíferos, durante el proceso de resolución del rigor mortis se alcancen valores de $\mathrm{pH}$ más elevados que en la carne de mamíferos.

El número y el tamaño de las fibras musculares (celularidad muscular), están directamente relacionados con las características instrumentales de textura, de la carne del pescado fresco, ya que numerosos estudios han demostrado una correlación positiva entre el tamaño y la densidad de las fibras musculares y la dureza de la carne (Hatae y col., 1990; Hurling y col., 1996; Periago y col., 2005), relación que también ha sido observada en pescado procesado (Johnston, 1999; Ayala y col., 2010 y 2011). Por otro lado, tal y como demuestran (Bjerkeng y col., 
1997; Røra ${ }^{\circ}$ y col., 1998; Rasmussen y Ostenfeld, 2000; Regost y col., 2001) la dieta y el contenido en grasa influyen en menor medida, aunque en periodo de desove se incrementa la dureza de la carne debido a un aumento proporcional del contenido en colágeno (Foegeding y col., 1996; Austreng y Krogdahl, 1987). Otros autores han descrito que la reducción de la dieta y los largos periodos de inanición disminuyen la dureza y aumentan la exudación, debido posiblemente a unas menores reservas de glucógeno a nivel del tejido muscular (Johansson y col., 1995; Regost y col., 2001; Einen y col., 1999).

El análisis sensorial del pescado cocinado puede ofrecer información adicional al análisis sensorial del pescado crudo, principalmente en atributos relacionados con el olor y el flavor, que juegan un papel importante en la apreciación de frescura (Pons y col., 2006). De hecho, este análisis es el que mejor se correlaciona con el criterio de calidad del consumidor (Pons y col., 2006), y es necesario recurrir a esquemas de valoración muy distintos de los aplicables al pescado crudo. Los métodos más comúnmente utilizados para la evaluación del pescado cocido son los esquemas Torry (Torry Research Station, 1989).

\section{OBJETIVOS}

Comprobar cómo afecta el método de presentación y conservación de doradas de acuicultura (enteras, fileteadas, fileteadas y envasadas al vacío y fileteadas marinadas y posteriormente envasadas al vacío), a la calidad sensorial del pescado durante el almacenamiento en hielo.

\section{MATERIAL Y MÉTODOS}

\section{Características de las muestras}

En el presente estudio se han analizado cuatro presentaciones diferentes de dorada de acuicultura: enteras, fileteadas, fileteadas y envasadas al vacío, fileteadas y marinadas con limón al vacío. Para cada presentación se emplearon 15 ejemplares de dorada (Sparus aurata), cultivadas en jaulas en la costa mediterránea por la empresa Martorres (Guadarmar, Alicante). Las doradas de tamaño comercial $(\approx 30 \mathrm{~cm}$ de longitud; $\approx 400 \mathrm{~g}$ de peso), habían sido alimentados ad libitum con pienso comercial, y extraídos de la población general, según las prácticas de la empresa. Todos los especímenes fueron capturados siguiendo el mismo procedimiento, subiendo a los peces a la superficie con ayuda de una red, e introducirlos en un tanque con hielo, lo que produce la entrada en shock térmico, quedando aturdidos y muriendo rápidamente por asfixia.

En cada una de las presentaciones, las 15 muestras fueron clasificadas en lotes de tres ejemplares, siendo analizados a su llegada y a los 5, 10, 15 y 22 días tras la captura, para evaluar la evolución de los distintos parámetros sensoriales. Durante el tiempo de almacenamiento se mantuvieron en hielo, que se reponía regularmente, y en cámara de refrigeración, hasta el momento del análisis. La Figura 1 muestra las diferentes presentaciones de las doradas empleadas en nuestro estudio.

En el caso de las doradas enteras, la empresa Martorres fue la encargada de transportar las muestras recién sacrificadas, a la Facultad de Veterinaria de la Universidad de Murcia, introducidas en cajas de poliestireno y cubiertas con hielo (ratio pescado/hielo 1:2). Así mismo, la citada empresa realizó el fileteado industrial de los ejemplares de dorada, empleadas para las siguientes presentaciones, en el mismo día del sacrificio.

Para envasar los filetes al vacío las muestras se introdujeron en bolsas gofradas PA/PE $80 / 20$, de $100 \mu \mathrm{m}$ de espesor total, con una permeabilidad al oxígeno de $50 \mathrm{~cm}^{3} \mathrm{~m}^{-2}$ día $^{-1}$ bar $^{1}$ y al vapor de agua de $2.3 \mathrm{~g} \cdot \mathrm{m}^{-2} \cdot \mathrm{día}^{-1}\left(\mathrm{~T}^{\mathrm{a}}\right.$ $23^{\circ} \mathrm{C}$ y $0 \%$ de HR), envasándose al vacío con una envasadora ORVED Proffesional Family (ORVED srl unipersonale, Italia) con un nivel de vacío final de 0.15 bar. 


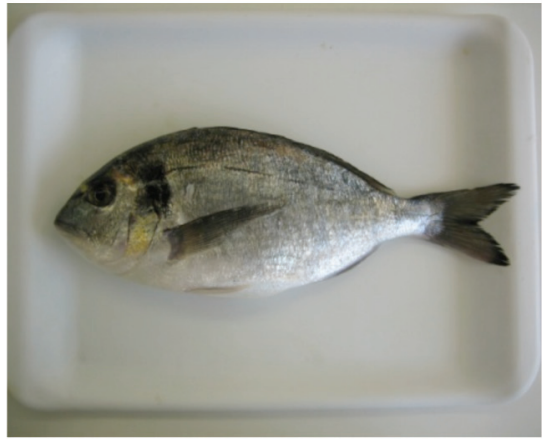

a)

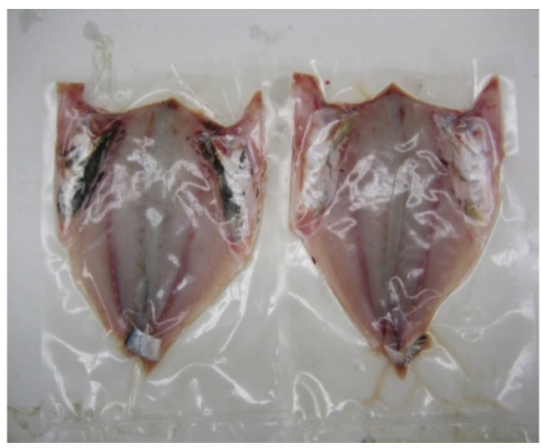

c)

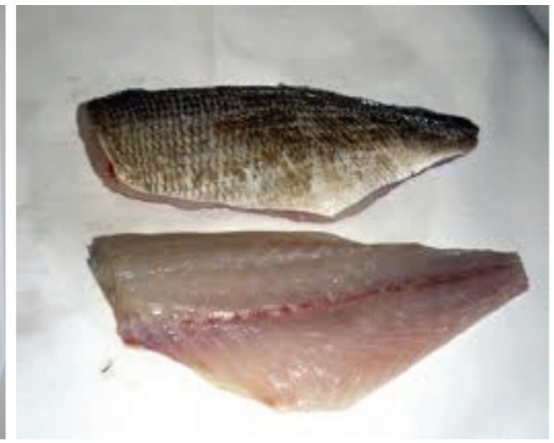

b)

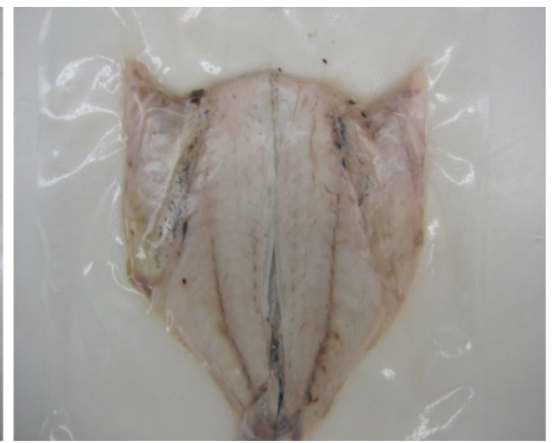

d)

Figura 1. a) enteras, b) fileteadas, c) fileteadas al vacío y d) fileteadas marinadas y envasadas al vacío.

Para la presentación de filetes marinados y envasados al vacío, se realizó el marinado de los filetes sumergiéndolos durante 1 hora en zumo de limón con $5.5 \%$ de $\mathrm{NaCl}$. El zumo de limón fue obtenido de forma natural, exprimiendo 20 $\mathrm{Kg}$ de limones adquiridos comercialmente. La acidez titulable del zumo fue de $48.9 \mathrm{~g}$ de ácido cítrico por litro de zumo. Posteriormente, los filetes se escurrieron y se envasaron al vacío siguiendo la misma metodología y materiales descritos anteriormente. Tanto el envasado al vacío como el marinado, se llevaron a cabo en el laboratorio del Área de Nutrición y Bromatología, de la Facultad de Veterinaria de la Universidad de Murcia.

\section{Análisis sensorial}

El procedimiento utilizado en la evaluación de la calidad sensorial consistió en una adaptación de los métodos descritos para doradas por Alasalvar y col. (2002) (modificación del esquema reseñado en Torry advisory note No. 91, 1989), y por Huidobro y col. (2000).

Todas las determinaciones se llevaron a cabo en el laboratorio de evaluación sensorial, situado en el Departamento de Tecnología de Alimentos, Nutrición y Bromatología, según la norma ISO 8589:2007, que cuenta con las siguientes condiciones: siete cabinas de degustación, provistas de lámparas regulables en in- 
Tabla 2. Esquema para la evaluación sensorial de los filetes cocinados

\begin{tabular}{|c|c|c|c|c|}
\hline Puntuación & Apariencia & Olor & Flavor & Textura \\
\hline 10 & $\begin{array}{l}\text { Característica de pesca- } \\
\text { do cocido, brillante }\end{array}$ & $\begin{array}{l}\text { Característico, ligera- } \\
\text { mente dulce }\end{array}$ & $\begin{array}{l}\text { Característico, muy } \\
\text { suculento }\end{array}$ & $\begin{array}{l}\text { Firme y elástica, se des- } \\
\text { menuza con facilidad }\end{array}$ \\
\hline 9 & $\begin{array}{l}\text { Característica, menos } \\
\text { intensa }\end{array}$ & $\begin{array}{l}\text { Característico menos in- } \\
\text { tenso, carne cocida }\end{array}$ & Característico, suculento & Menos firme y elástica \\
\hline 8 & Ligeramente apagada & $\begin{array}{l}\text { Característico menos in- } \\
\text { tenso, a leche o patatas } \\
\text { cocidas }\end{array}$ & $\begin{array}{l}\text { Característico, menos } \\
\text { intenso, suculento }\end{array}$ & Menos elástica \\
\hline 7 & Reseca & Neutro, patatas cocidas & $\begin{array}{l}\text { Neutro, un poco dulce, } \\
\text { insípido }\end{array}$ & Blanda \\
\hline 6 & $\begin{array}{l}\text { Aumento del atributo } \\
\text { anterior }\end{array}$ & Dulce, afrutado & Un poco metálico, seco & Muy blanda \\
\hline 5 & Aspecto gelatinoso & A pescado & $\begin{array}{l}\text { Un poco agrio, ácido o } \\
\text { rancio }\end{array}$ & Pastosa \\
\hline 4 & $\begin{array}{l}\text { Presencia de abundante } \\
\text { exudado lechoso }\end{array}$ & $\begin{array}{l}\text { Olor intenso a pescado, } \\
\text { ácido, agrio }\end{array}$ & $\begin{array}{l}\text { Amargo, agrio, rancio, } \\
\text { picante }\end{array}$ & $\begin{array}{l}\text { Aumento del atributo } \\
\text { anterior }\end{array}$ \\
\hline 3 & $\begin{array}{l}\text { Aumento del atributo } \\
\text { anterior }\end{array}$ & $\begin{array}{l}\text { Ácido láctico, } \\
\text { amoniacal, rancio }\end{array}$ & Amoniacal, muy picante & Muy pastosa \\
\hline
\end{tabular}

tensidad y ventanilla con pasaplatos, zona destinada a la preparación de muestra, cocina, zona de almacén de material y zona de reuniones y puesta en común. La sala de catas está ubicada en una zona de escasa afluencia, con lo que se limitan las posibles interferencias a la hora de realizar las determinaciones.

El panel de catadores se formó con seis panelistas, familiarizados con la determinación de frescura del pescado, pertenecientes al Área de Conocimiento de Nutrición y Bromatología. Los panelistas tenían conocimientos previos de los principios elementales de las técnicas utilizadas en el análisis sensorial. Habían desarrollado aptitudes para detectar, reconocer y describir estímulos sensoriales, mediante pruebas de identificación de sabores u olores, así como descripción de la textura (UNE 87-0241:95). Previo al análisis se llevaron a cabo dos sesiones de familiarización, para asegurar que los jueces entendían los atributos sensoriales a evaluar. Los parámetros evaluados fueron apariencia, olor, flavor y textura.
Basándonos en los estudios previos realizados por distintos autores para diferentes especies de pescado cocinado y que se encuentra en la literatura científica, (Huidrobo y col., 2000; Alasalvar y col., 2001; Kyrana y Lougovois, 2002; Pons y col., 2006), se elaboró un esquema con las características a evaluar y la relación con una escala puntuada, que oscilaba entre 10 y 3 , correspondiéndose 10 con pescado absolutamente fresco, y 3 con pescado completamente deteriorado, que fue entregado a cada catador a la hora de realizar el test de calidad organoléptica o sensorial (Tabla 2).

El análisis sensorial, se realizó el día de llegada de las muestras al Departamento, correspondiendo esta determinación con la referencia de pescado absolutamente fresco, y a los 5, 10, 15 y 22 días de permanencia en hielo, y se emplearon 3 ejemplares de cada presentación. En el caso de las doradas enteras, se llevó a cabo un fileteado manual de las mismas, para realizar el cocinado previo al análisis sensorial, en las mismas condiciones que en los demás estudios. 
A cada panelista se le proporcionó una porción de filete que se correspondía con la musculatura dorsal de media dorada. Los filetes fueron cocinados en horno microondas a 750 W durante 3 minutos y servidos a los panelistas inmediatamente después de ser cocinados.

\section{Análisis Estadístico}

El análisis estadístico de los resultados obtenidos fue realizado con el paquete estadístico SPSS para Windows, versión 15.0 (SPSS Inc, Chicago IL). En primer lugar se realizó un análisis descriptivo, expresando los resultados como media y error típico de las determinaciones realizadas. Para establecer la influencia del tiempo de almacenamiento en la apreciación global de frescura, para cada una de las presentaciones, se realizó un análisis de la varianza (ANOVA), teniendo en cuenta un nivel de significación $\mathrm{p}<0.05$. También se realizó un test de Tuckey para la comparación de las medias por parejas.

\section{RESULTADOS Y DISCUSIÓN}

La Figura 2, muestra la apreciación global de frescura de los filetes cocinados, con respecto al tiempo de almacenamiento. La puntuación otorgada por los seis panelistas para cada uno de los atributos (apariencia, olor, flavor y textura) fue promediada para obtener la puntuación media global que concede el panel en cada día de almacenamiento, para cada una de las presentaciones, y que denominamos apreciación global de frescura.

En las cuatro presentaciones, las puntuaciones otorgadas por el panel de catadores para la frescura decrecieron a medida que pasan los días de permanencia en hielo. Una puntuación global de 4 , (que se corresponde con presencia de exudado blanco, olor ácido o agrio, sabor amargo y picante y textura blanda y pastosa), fue considerada inaceptable por los miembros del panel, siendo motivo de rechazo sensorial.

En el día 22 de permanencia en hielo esta puntuación global de 4 es alcanzada en doradas

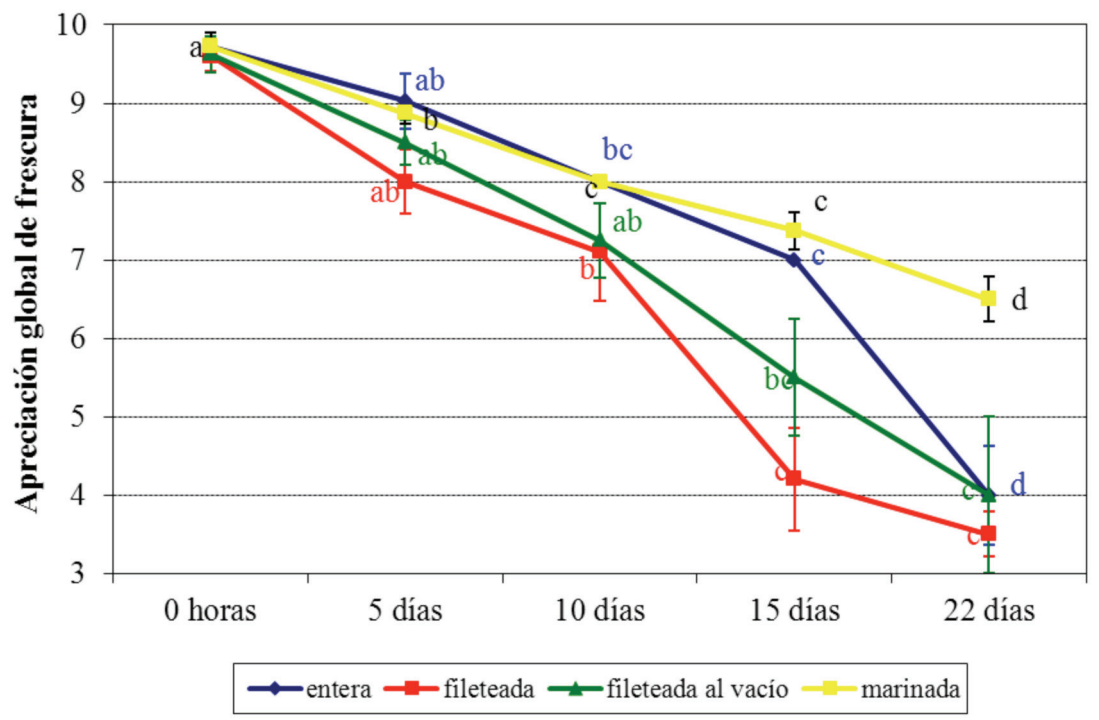

Figura 2. Cambio en la apreciación global de frescura, de las doradas enteras, fileteadas, fileteadas al vacío, y marinadas, con el tiempo de permanencia en hielo. Cada punto representa la media de seis panelistas. Las barras verticales representan el error típico. Diferentes letras en el mismo tratamiento significan diferencias estadísticamente significativas para $\mathrm{P}<0.05$. 

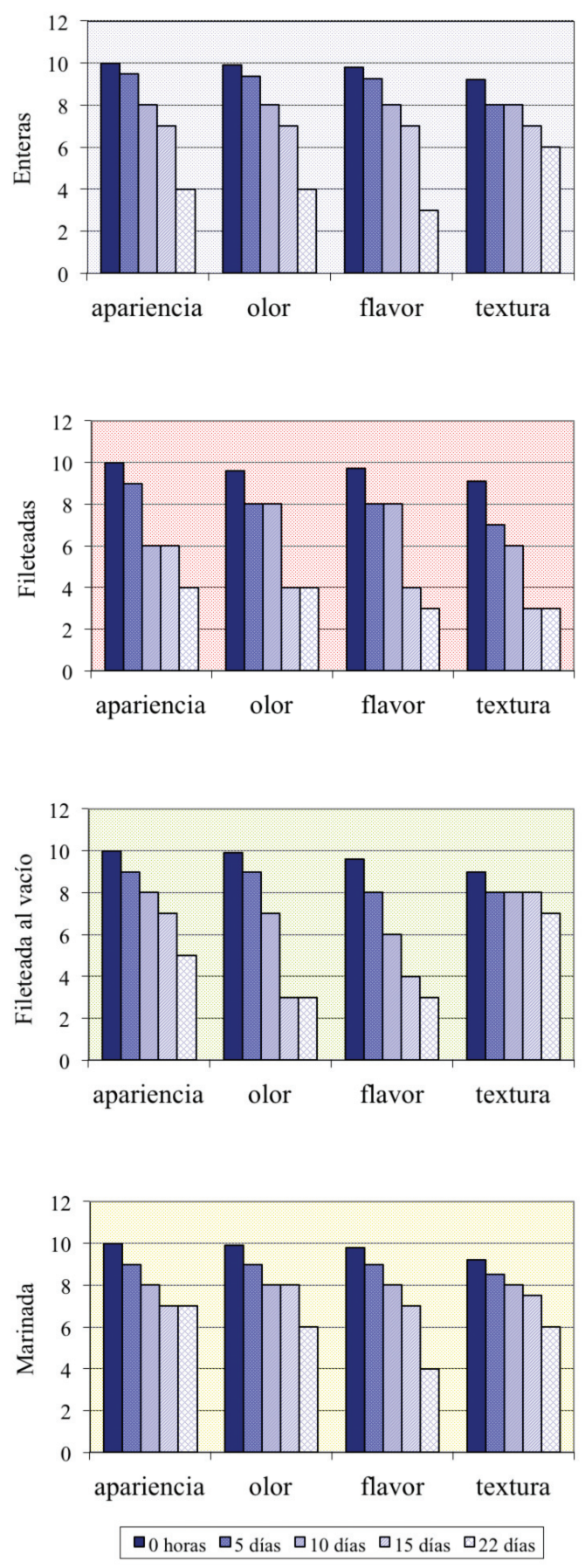

Figura 3. Evolución de los atributos sensoriales en doradas enteras; fileteadas; fileteadas al vacío; y marinadas. enteras, doradas fileteadas y doradas fileteadas al vacío, sin embargo, las doradas marinadas no llegaron a alcanzarla en los 22 días de almacenamiento. En las cuatro presentaciones, las características propias de pescado fresco cocinado (olor ligeramente dulce, sabor jugoso y suculento, y textura firme y elástica), son característicos del primer día de análisis, y van decreciendo en intensidad de forma gradual hasta el día 15, en el caso de doradas enteras y marinadas, y más drásticamente, a partir del día 10 , en el caso de fileteadas y fileteadas al vacío. En la Figura 2 podemos observar como las puntuaciones obtenidas en el día 15 de almacenamiento en las doradas fileteadas se aproximaron a 4 (valor de rechazo), y fueron muy inferiores a las obtenidas en los otros tres estudios.

Estos datos coinciden con los obtenidos por Kyrana y col. (1997), Huidrobo y col. (2000) y Alasalvar y col. (2001 y 2002), para dorada cocinada. Estos autores realizaron un estudio paralelo con el pescado entero, sin cocinar, siguiendo el método QIM o modificaciones del sistema TFRU (CSIRO, 1984), y llegaron a la conclusión de que, aunque la dorada fresca mantenida en hielo, se considera deteriorada a partir del día 15-18 de almacenamiento en hielo, ese mismo pescado si se cocina, todavía es evaluado como aceptable por un panel de catadores. Este hecho puede atribuirse a dos causas, por un lado el cocinado podría estar enmascarando los cambios adversos que se observan en el pescado crudo, siempre que estos cambios no sean muy extremos, y por otro lado el calor derivado del tratamiento culinario podría estar liberando muchos de los olores desagradables que sí se detectan en el pescado crudo.

La Figura 3, muestra cómo evolucionan los atributos sensoriales (apariencia, olor, flavor y textura), en cada una de las presentaciones. Podemos observar, como las doradas enteras mantuvieron todos los atributos por encima de 7 hasta el día 15 , descendiendo drásticamente en el día 22 la apariencia, el olor y el flavor. La textura por el contrario se mantuvo con va- 
lores de 6 incluso en el último día de muestreo, ya que el pescado lo conservamos entero, sin filetear ni eviscerar, y la textura en este caso sólo va a modificarse por causas endógenas, no por la acción mecánica externa del fileteado, que supone el corte de las fibras musculares (Delbarre-Ladrat y col., 2006).

Las doradas fileteadas, obtuvieron puntuaciones de 4 en olor, flavor y textura, a partir del día 15 , y en el día 22 todos los atributos se encontraron por debajo de ese valor. Las doradas fileteadas y envasadas al vacío presentaron mejores resultados en textura y apariencia, ya que, mantienen puntuaciones de 5 o superiores en estos atributos hasta el día 15, y en el día 22 la textura todavía se mantuvo por encima de 4 . Este hecho lo atribuimos a que el envasado al vacío por un lado, al limitar el oxígeno disponible disminuye la oxidación, y por otro evita la pérdida de agua y el secado superficial, con lo que mejora la apariencia del producto, y como observamos con anterioridad también es beneficioso para el mantenimiento de la textura. Por lo tanto, el fileteado, si no va acompañado de algún método de conservación adicional, disminuye la vida útil del pescado, ya que cualquier tipo de manipulación que llevemos a cabo sobre el pescado, va a ocasionar que el producto se encuentre más expuesto a factores externos, sin olvidar que la manipulación asociada al fileteado va a favorecer la contaminación bacteriana, aumentando el crecimiento de microorganismos relacionados con el deterioro (Tejada y Huidrobo; 2002).

Es destacable el hecho, de que en el día 15 hubo un descenso brusco en las puntuaciones otorgadas a los parámetros de flavor y olor, tanto en doradas fileteadas como fileteadas al vacío. Este descenso puede estar asociado al aumento significativo de la concentración de nitrógeno de trimetilamina, responsable del olor desagradable del pescado deteriorado. Numerosos autores han estudiado, el aumento progresivo de la concentración de este compuesto en pescado, y particularmente en dorada, a medida que transcurren los días de permanencia en hie- lo (Chouliara y col., 2004; Goulas y Kontominas, 2007)

Las doradas marinadas presentaron puntuaciones medias en los atributos sensoriales de 6 en el día 22 de almacenamiento, excepto en el flavor donde el valor obtenido es de 4. Que sea la presentación que mejores resultados sensoriales obtuvo, fue debió a que el marinado proporcionó al producto características de olor y sabor propias del limón, enmascarando en cierta medida los del pescado, a este hecho, se une que el zumo de limón con cloruro sódico tiene una marcada actividad antimicrobiana, inhibiendo el crecimiento de bacterias específicas del deterioro, debido a su alta concentración en ácidos orgánicos, y a su capacidad de reducir la actividad agua del producto (Gökoglu y col., 2004 y 2009). De esta manera no aparecen de forma temprana las alteraciones características, como son el olor desagradable, el ablandamiento, pastosidad o el limo superficial.

Por otro lado, el marinado proporciona una mayor textura a la carne del pescado. La textura refleja los cambios que se producen en las proteínas musculares tras la muerte, así, los primeros cambios que tienen lugar se deben a la actividad de enzimas endógenas como calpainas y catepsinas, que provocan la proteolisis de los componentes del citoesqueleto (Delbarre-Ladrat y col., 2006). Estos cambios post-mortem, unidos a la degradación de las fibras de colágeno llevada a cabo por enzimas colagenasas, y al deterioro bacteriano, son responsables en gran medida de la pérdida de textura del pescado (Delbarre-Ladrat y col., 2006; Taylor y col., 2002). Numerosos autores han demostrado que la actividad autolítica, tanto de catepsinas como de otras proteasas endógenas, se ve disminuida al aumentar la concentración de cloruro sódico (Sirigan y col., 2006; Sen, 2005).

\section{CONCLUSIÓN}

La conservación de filetes mediante la técnica de marinado con zumo de limón y cloru- 
ro sódico incrementa la vida útil del producto, prolongando el tiempo de aceptación sensorial hasta 22 días tras su almacenamiento en hielo

\section{BIBLIOGRAFÍA}

ALASALVAR C., TAYLOR K.D.A., ÖKSÜZ A., GARTHWAITE T., ALEXIS M.N. Y GRIGORAKIS K. 2001. Freshness assessment of cultured sea bream (Sparus aurata) by chemical, physical and sensory methods. Foos chemistry 72: 33-40.

ALASALVAR C., TAYLOR K.D.A., ZUBCOB E., SHAHIDI F. Y ALEXIS M. 2002. Differentiation of cultured and wild sea bass (Dicentrarchus labrax) total lipid content, fatty acid and trace mineral composition. Food Chemistry 79: 145-150.

AUSTRENG E. Y KROGDAHL AÊ. 1987. Food quality of cultured salmonids. Feedstuffs 31: 12-13.

Ayala M.D., Abdel I., Santaella M., Martínez C., Periago M.J., Gil F., Blanco A. y López Albors O. (2010). Muscle tissue structural changes and texture development in sea bream, Sparus aurata L., during post-mortem storage. Food Science and Technology 43: 465-475.

AYALA M.D., SANTAELLA M., MARTÍNEZ C., PERIAGO M.J., BLANCO A. VÁZQUEZ J.M. Y LÓPEZ ALBORS O. 2011. Muscle tissue structure and flesh texture in gilthead sea bream, Sparus aurata L., fillets preserved by refrigeration and by vacuum packaging. Food Science and Technology 44: 1098-1106.

BJERKENG B., REFSTIE S., FJALESTAD K.T., STOREBAKKEN T., RÜDBOTTEN M. Y ROEM A.J. 1997. Quality parameters of the flesh of Atlantic salmon (Salmo salar) as affected by dietary fat content and full-fat soybean meal as a partial substitute for fish meal in the diet. Aquaculture 157: 297-309.

CADWALLADER K.R. 2000. Enzymes and flavor biogenesis fish. En: Seafood Enzy- mes. Utilization and Influence on Postharvest Seafood Quality. Pp 365-383. Eds. Haard N.F y. Simpson B.K. Marcel Dekker. New York.

CHOULIARA I., SAVVAIDIS I.N., PANAGIOTAKIS N. y KONTOMINAS M.G. 2004. Preservation of salted, vacuum-packaged, refrigerated sea bream (Sparks aurata) fillets by irradiation: microbiological, chemicals and sensory attributes. Food Microbiology 21: 351-359.

CONNELL J.J. 1990. Methods of assessing and selecting for quality. En: Control of fish quality. Pp. 122-150. Ed. Connell J.J.Oxford: Fishing News Books.

CSIRO Division of Food Research. 1984. Annual report. CSIRO Division of food Research. Canberra. Australia.

DALGAARD P. 2003. Fish, Spoilage of Seafood. En: Encyclopaedia of Food Science and Nutrition. Elsevier Science.

DELBARRE-LADRAT C., CHERET R., TAYLOR R. y VERREZ-BAGNIS V. 2006. Trends in postmortem aging in fish: Understanding of proteolysis and disorganisation of the Myofibrillar Structure Critical Reviews. En: Food Science and Nutrition 46 (5): 409 $-421$

EINEN O., MØRKØRE T., RØRA ${ }^{\circ}$ A.M.B. Y THOMASSEN M.S. 1999. Feed ration prior to slaughter -a potential tool for managing product quality of Atlantic salmon (Salmo salar). Aquaculture 178: 149-169.

FOEGEDING E.A., LANIER T.C. Y HULTIN H.O. 1996. Characteristics of edible muscle tissues. En: Food Chemistry. Pp. 879-942. Ed. Fennema O.R. Marcel Dekker. N.Y., USA.

GOKOGLU N., CENGIZ E. y YERLIIKAYA P. 2004. Determination of the shelf life of marinated sardine (Sardina pilchardus) stored at $4{ }^{\circ} \mathrm{C}$. Food control 15: 1-4.

GOKOGLU N., KADIR-TOPUZ O. y YERLINKAYA P. 2009. Effects of pomegranate sauce on quality of marinated anchovy du- 
ring refrigerated storage. LWT-Food Science and Technology 42: 113-118.

GOULAS A.E. y KONTOMINAS M.G. 2007. Combined effect of light salting, modified atmosphere packaging and oregano essential oil on the shelf-life of sea bream (Sparus aurata): Biochemical and sensory attributes. Food Chemistry 100: 287-296.

HATAE K., YOSHIMATSU F. Y MATSUMOTO J.J. 1990. Role of muscle fibers in contributing firmness of cooked fish. Journal of Food Science 55: 693-696.

HUIDOBRO A., PASTOR A. Y TEJADA M. 2000. Quality index method developed for raw gilthead seabream (Sparus aurata). J Food Sci. 65 (7): 1202-1205.

HURLING R., RODELL J.B. y HUNT H.D. 1996. Fiber diameter and fish textural. J. Texture Stud. 27: 679-685.

HUSS H.H. 1999. El pescado fresco: su calidad y cambios de su calidad. Documento Técnico de pesca 348. Organización de las Naciones Unidas para la Agricultura y la Alimentación, FAO, Roma, Italia.

ISO 8589:2007. 2010. Análisis sensorial. Guía general para el diseño de salas de cata. CEN (Comité Europeo de Normalización).

JOHANSSON L., KIESSLING A., ASGARD T. Y BERGLUND L. 1995. Effects of ration level in rainbow trout Oncorhynchus mykiss (Walbaum), on sensory characteristics, lipid content and fatty acid composition. Aquaculture Nutrition 1: 59-66.

JOHNSTON I.A. 1999. Muscle development and growth: potential implications for flesh quality in fish. Aquaculture 177: 99-115.

KYRANA V.R. Y LOUGOVOIS V.P. 2002. Sensory, chemical and microbiological assessment of farm raised European sea-bass (Dicentrarchus labrax) stored in melting ice. International Journal of Food Science and Technology. 37: 319-328.

KYRANA V.R., LOUGOVOIS V.P. Y VALSAMIS D.S. 1997. Assessment of shelf-life of maricultured gilhead sea bream (Sparus au- rata) stored in ice. International Journal of Food Science and Technology 32: 339-347.

LOVE R.M. 1980. Biological factors affecting processing and utilization. En: Advances in Fish Science and Technology. Pp. 130-138. Ed. Connell J.J. Fishing News Books. Farnham, UK.

LUDOVICO-PELAYO L., HULME A. Y LOVE R.M. 1984. Seasonal variations in flavour change of cold-stored rainbow trout. En: Thermal Processing and Quality of Foods. Pp. 659-663. Eds. Zeuthen P., Cheftel J.C., Eriksson C., Jul M., Leniger H., Linko P., Varela G. y G. Vos. Elsevier Applied Science Publishers. Londres, UK.

OCAÑO-HIGUERA V.M., MARQUEZ-RÍOS E., CANIZALES-DÁVILA M., CASTILLO-YÁÑEZ F.J., PACHECO-AGUILAR R., LUGO-SÁNCHEZ M.E., GARCÍAOROZCO K.D. Y GRACIANO-VERDUGO A. 2009. Postmortem changes in cazon fish muscle stored on ice. Food Chemistry 116 (4): 933-938.

PERIAGO M.J., AYALA M.D., LÓPEZALBORS O., ABDEL I., MARTÍNEZ C., GARCÍA-ALCAZAR A., ROS G. Y GIL F. 2005. Muscle cellularity and flesh quality of wild and farmed sea bass, Dicentrarchus labrax L. Aquaculture 249: 175-188.

PONS S., VIDAL M.C., NUDES M.T. Y VECIANA M.T. 2006. Sensory analysis to assess the freshness of Mediterranean anchovies (Engraulis encrasicholus) stored in ice. Food Control 17: 564-569.

RASMUSSEN R. S. 2001. Quality of farmed salmonids with emphasis on proximate composition, yield and sensory characteristics. Aquaculture Research 32: 767-786.

RASMUSSEN R.S. Y OSTENFELD T.H. 2000. Effect of growth rate on quality traits and feed utilization of rainbow trout (Oncorhynchus mykiss) and brook trout (Salvelinus fontinalis). Aquaculture 184: 327-337.

REGOST C., ARZEL J., CARDINAL M., LAROCHE M. Y KAUSHIK S.J. 2001. Fat 
deposition and flesh quality in seawater reared triploid brown trout (Salmo trutta) as affected by dietary fat levels and starvation. Aquacultur 193: 325-345.

RØRA ${ }^{\circ}$. A.M.B., KVA LE A., MØRKØRE T., RØRVIK K.A., STEIEN S.H. Y THOMASSEN M.S. 1998. Process yield, colour and sensory quality of smoked Atlantic salmon (Salmo salar) in relation to raw material characteristics. Food Research International 31: 601-609.

SEN D.P. 2005. En: Advances in Fish Processing Technology. Allied Publisher Private Limited, Mumbai, India.

SIRIGAN P., RAKSAKULTHAI N. y YONGSAWATDIGUL J. 2006. Autolytic activity and biochemical characteristics of endogenous proteinases in Indian anchovy
(Stolephorus indicus). Food Chem. 98: 678684.

TAYLOR R.G., FJAERA S.O. y SKJERVOLD, P.O. 2002. Salmon fillet texture is determined by myofiberemyofiber and myofiberemyocommata attachment. Journal of Food Science. 67: 2067-2071.

TEJADA M. Y HUIDROBO A. 2002. Quality of farmed gilthead seabream (Sparus aurata) during ice storage related to slaughter method and gutting. Eur. Food Res. Technol. 215:1-7.

TORRY ADVISORY NOTE NO. 91. 1989. Aberdeen: Torry Research Station and Ministry of Agriculture and Fisheries MAFF.

UNE 87-024-1:95. 1995. Análisis Sensorial. Guía general para la selección, entrenamiento y control de jueces. AENOR 